\title{
Ammonia scavenging agents for people with cirrhosis and hepatic encephalopathy
}

\section{Protocol information}

Review type: Intervention

Authors

Harry D Zacharias ${ }^{1}$, Antony P Zacharias ${ }^{1}$, Alexandre Oliveira Ferreira ${ }^{2}$, Marsha Y Morgan ${ }^{1}$, Lise Lotte Gluud ${ }^{3}$

${ }^{1}$ UCL Institute for Liver \& Digestive Health, Division of Medicine, Royal Free Campus, University College London,

London, UK

2Department of Gastroenterology and Hepatology, Hospital Santa Maria, Lisboa, Portugal

${ }^{3}$ Gastrounit, Medical Division, Copenhagen University Hospital Hvidovre, Hvidovre, Denmark

Citation example: Zacharias HD, Zacharias AP, Oliveira Ferreira A, Morgan MY, Gluud LL. Ammonia scavenging agents for people with cirrhosis and hepatic encephalopathy. Cochrane Database of Systematic Reviews 2016, Issue 8 . Art. No.: CD012334. DOI: 10.1002/14651858.CD012334.

Contact person

Lise Lotte Gluud

Consultant

Gastrounit, Medical Division

Copenhagen University Hospital Hvidovre

Kettegaards Alle

Hvidovre

2650

Denmark

E-mail: liselottegluud@yahoo.dk

Dates

Assessed as Up-to-date:Not provided

Date of Search: Not provided

Next Stage Expected: 4 September 2016

Protocol First Published: Issue 8, 2016

Review First Published: Not specified

Last Citation Issue: Issue 8, 2016

What's new

\begin{tabular}{l|l|l|}
\hline Date & Event & Description \\
History & \multicolumn{2}{|l|}{} \\
\hline Date & Event & Description \\
\hline
\end{tabular}

Abstract

Background

Objectives

Search methods

Selection criteria

Data collection and analysis

Main results

Authors' conclusions

Plain language summary

[Summary title]

[Summary text]

\section{Background}

Description of the condition

Definition and terminology 
The term 'hepatic encephalopathy' refers to a spectrum of neuropsychiatric changes occurring in people with liver insufficiency or portal-systemic shunting (AASLD and EASL Guideline 2014a; AASLD and EASL Guideline 2014b). The term 'minimal' hepatic encephalopathy (in the older literature 'subclinical' or 'latent') refers to people with cirrhosis who are 'clinically normal', but who show abnormalities in neuropsychometric or neurophysiological performance (Ferenci 2002). Changes in mental state range from subtle alterations in cognitive function to profound alterations in consciousness leading to deep coma with decerebrate posturing. Clinically apparent or 'overt' hepatic encephalopathy manifests as a neuropsychiatric syndrome encompassing a wide spectrum of mental and motor disorders (Weissenborn 1998; Ferenci 2002). Events such as gastrointestinal bleeding, infection, and alcohol misuse can trigger this so-called 'acute' or 'episodic'hepatic encephalopathy. Fifty per cent of instances occur with no obvious cause. After an episode, people may return to their baseline neuropsychiatric status or show clinical evidence of impairment (Bajaj 2010). Less frequently, people present with persistent neuropsychiatric abnormalities, often due to extensive spontaneous portal-systemic shunting or after insertion of a transjugular intrahepatic portosystemic shunt (TIPS). Patients may experience asterixis (flapping tremor) or a variety of other changes in motor function (Victor 1965; Weissenborn 1998; Cadranel 2001). Overt hepatic encephalopathy is also associated with impaired psychometric performance (Schomerus 1998), disturbed neurophysiological function (Chu 1997), altered cerebral neurochemical/neurotransmitter homeostasis (Taylor-Robinson 1994), reductions in global and regional cerebral blood flow and metabolism (O'Carroll 1991), and changes in cerebral fluid homeostasis (Haussinger 2000). For most people, the degree of impairment increases as the clinical condition worsens.

\section{Diagnosing hepatic encephalopathy}

The diagnosis of hepatic encephalopathy may present no problems, but without the background information and an obvious precipitating event, hepatic encephalopathy may go unrecognised. We have no gold standard for the diagnosis (Montagnese 2004; AASLD and EASL Guideline 2014a; AASLD and EASL Guideline 2014b), but rather techniques which we can use singly or in combination. The diagnosis of overt hepatic encephalopathy requires a detailed neuropsychiatric history and examination (Montagnese 2004) with particular attention paid to changes in memory, concentration, cognition, and consciousness. Clinicians and researchers often use the West Haven criteria to grade mental state (Conn 1977) and the Glasgow Coma Score to grade the level of consciousness (Teasdale 1974). The neurological examination looks for evidence of subtle motor abnormalities and excludes other potential causes of neuropsychiatric abnormalities including neurological disorders and metabolic abnormalities. People with hepatic encephalopathy have impaired psychometric performance (Montagnese 2004; $\underline{\text { Randolph }}$ 2009). Those with minimal hepatic encephalopathy show deficits in attention, visuo-spatial abilities, fine motor skills, and memory, while their other cognitive functions are relatively well preserved. People with overt hepatic encephalopathy show additional disturbances in psychomotor speed, executive function, and concentration. Psychometric test batteries to assess cognitive function form part of the evaluation. The Psychometric Hepatic Encephalopathy Score has a high specificity for the diagnosis (Schomerus 1998; Weissenborn 2001). The test employs five paper and pencil tests to assess attention, visual perception, and visuo-constructive abilities. Test scores have to be normalised to take account of factors such as age, sex, and educational level. At present, normative databases are available in Germany, Italy, Denmark, Spain, Mexico, Korea, India, and Great Britain. People with hepatic encephalopathy may also have neurophysiological abnormalities (Guérit 2009). The electroencephalogram may show progressive slowing of the background activity and abnormal wave morphology. Other potential diagnostic techniques include the Critical Flicker Fusion Frequency (Kircheis 2002) and the Inhibitory Control Test (Bajaj 2008). The tests need further validation.

\section{Description of the intervention}

Ammonia plays a key role in the development of hepatic encephalopathy (Butterworth 2014). Ammonia scavengers are agents developed for the reduction of blood ammonia concentration used for the treatment of children with urea cycle disorders (Berry 2014). The available scavenging drugs (Table 1) tested for people with hepatic encephalopathy include AST-120 (Spherical Carbon Adsorbent), glycerol phenylbutyrate, and ornithine phenylacetate, which is a combination of L-ornithine and phenylacetate (Sushma 1992; Efrati 2000; Jalan 2007; Bosoi 2011; Misel 2013; Ventura-Cots 2013; Wu 2014; Rahimi 2016). The adverse events associated with the use of these drugs are mainly gastrointestinal and include diarrhoea, constipation, dry mouth, and changes in appetite (Lee 2010).

\section{How the intervention might work}

The pathogenesis of hepatic encephalopathy is complex. The disease is multifactorial with accumulation of toxins, chronic inflammation, and ion abnormalities. Increased levels of ammonia play a key role (Butterworth 2013; Butterworth 2014). A number of interventions for the management of hepatic encephalopathy aim at decreasing the absorption of ammonia through a reduction in intestinal transit or altering the microbiome. Current guidelines recommend nonabsorbable disaccharides as the treatment of choice (AASLD and EASL Guideline 2014a; AASLD and EASL Guideline 2014b; Gluud 2016a; Gluud 2016b). The antibiotic rifaximin, which is a poorly absorbed antibiotic, is used as an add-on therapy for the prevention of recurrent episodes (Bass 2010). Ammonia scavengers are a new potential treatment option (McGuire 2010; Rose 2012; Jover-Cobos 2013). These drugs primarily work by increasing the excretion of ammonia through alternative pathways for the metabolism of glutamine (Table 1).

\section{Why it is important to do this review}

Hepatic encephalopathy is a serious complication to cirrhosis and puts a considerable burden on the people affected, their families, and healthcare systems (Stepanova 2012). Ammonia scavenging agents may be effective as 
Ammonia scavenging agents for people with cirrhosis and hepatic encephalopathy

an alternative or add-on intervention, as shown by their ability to reduce ammonia levels. In spite of their theoretical effect, randomised clinical trials (RCTs) are needed to determine the clinical effects (McGuire 2010; Rockey 2014). At present, there are only a few published RCTs, but ongoing and planned RCTs are expected to increase the strength of the evidence in the near future (Bajaj 2013; Pockros 2009; Sherker 2009; Rockey 2014; NCT01966419; NCT00558038). We therefore decided to conduct this systematic review evaluating the effect of ammonia scavenging agents for people with cirrhosis and hepatic encephalopathy.

\section{Objectives}

To evaluate the benefits and harms of ammonia scavenging agents versus placebo, no intervention, or other active interventions for people with cirrhosis and hepatic encephalopathy.

\section{Methods}

\section{Criteria for considering studies for this review \\ Types of studies}

We will include randomised clinical trials (RCTs), irrespective of blinding, language, or publication status. We will include quasi-randomised studies and observational studies in the analyses of adverse events.

\section{Types of participants}

We will include RCTs evaluating people with cirrhosis and hepatic encephalopathy regardless of age or underlying aetiology. We will include RCTs evaluating prevention or treatment of hepatic encephalopathy (overt or minimal).

\section{Types of interventions}

We will evaluate ammonia scavenging agents (including glycerol phenylbutyrate, ornithine phenylacetate, and spherical carbon adsorbents also known as AST-120) versus placebo or no intervention or interventions with a potential effect on hepatic encephalopathy (such as non-absorbable disaccharides or antibiotics). Co-interventions administered equally to the intervention and control groups are allowed.

We will not include studies of L-ornithine L-aspartate in this review due to overlap with another Cochrane review (Stokes 2016).

\section{Types of outcome measures}

We will assess all outcomes at the maximum duration of follow-up (Gluud 2016c).

\section{Primary outcomes}

1. Mortality.

2. Hepatic encephalopathy. We will assess the outcome using the primary investigators' overall assessment of: i) number of participants who developed hepatic encephalopathy, and ii) number of participants without a clinically-relevant improvement in hepatic encephalopathy.

3. Serious adverse events: defined as any untoward medical occurrence that led to death, were life threatening, or required hospitalisation, or prolongation of hospitalisation (ICH-GCP). We will analyse these as a composite outcome (Gluud 2016c).

\section{Secondary outcomes}

1. Quality of life.

2. Non-serious adverse events (defined as all adverse events that do no fulfil the criteria listed under serious adverse events).

3. Liver-related mortality.

\section{Exploratory outcomes}

1. Blood ammonia levels.

2. Number Connection Test results.

\section{Search methods for identification of studies}

\section{Electronic searches}

We will search The Cochrane Hepato-Biliary Group Controlled Trials Register (Gluud 2016c), the Cochrane Central Register of Controlled Trials (CENTRAL), MEDLINE, Embase, and Science Citation Index Expanded. We will prepare the search strategies in collaboration with the Information Specialist of the Cochrane Hepato-Biliary Group. Preliminary search strategies with the expected time spans of the searches are given in Appendix 1.

\section{Searching other resources}

We will scan reference lists of relevant articles and conference proceedings (from the annual meetings of the American Association for the Study of Liver Diseases and the European Association for the Study of the Liver) and write to authors of trials and reviews on ammonia scavenging agents and pharmaceutical companies. We will also search online trial registries such as ClinicalTrial.gov (clinicaltrials.gov/),

European Medicines Agency (EMA) (www.ema.europa.eu/ema/), WHO International Clinical Trial Registry Platform (www.who.int/ictrp), and the Food and Drug Administration (FDA) (www.fda.gov), as well as pharmaceutical 
Ammonia scavenging agents for people with cirrhosis and hepatic encephalopathy

company sources for ongoing or unpublished trials.

\section{Data collection and analysis}

We will use the Cochrane Hepato-Biliary Group module (Gluud 2016c) and follow the Cochrane Handbook for Reviews of Interventions (Higgins 2011a) and the Methodological Expectations of Cochrane Intervention Reviews (MECIR) guidelines (MECIR 2014).

\section{Selection of studies}

All authors will participate in the identification and selection of included studies. Harry Zacharias and Antony Zacharias will determine suitability for inclusion, outlined in 'Criteria for considering studies for this review', by screening study titles and abstracts. We will retrieve the full texts of potentially eligible references and list included RCTs and excluded RCTs and studies with the reason for exclusion. For trials reported in more than one publication, we will select the paper reporting the longest duration of follow-up as the primary reference. We will list details of all included trials in summary tables and list all excluded studies with the reason for their exclusion.

\section{Data extraction and management}

Two review authors (Harry Zacharias and Antony Zacharias) will extract data from included trials. Disagreements will be solved through discussion. A third author (Marsha Y Morgan or Lise L Gluud) will act as ombudsman.

We will write to the primary investigators for additional unpublished information not contained in the trial reports. We will gather information about the following:

Trial: year and language of publication status; inclusion period; country; number of clinical sites; setting (inpatient or outpatient). Intervention: dose and duration of experimental and control intervention(s); co-interventions. Participants: characteristics (number/percent) of participants (inclusion criteria, age, sex, aetiology, proportion with alcoholic liver disease, proportion with viral hepatitis B/C); assessment of hepatic encephalopathy. Outcomes: outcomes in the trial including definitions used in the assessment and duration of follow up; Number of participants included in the assessment of outcomes (number of losses to follow-up/withdrawals); outcomes included in the meta-analyses.

\section{Assessment of risk of bias in included studies}

We will assess bias control using the domains described in the Cochrane Hepato-Biliary Group Module (Gluud 2016c ), and classify the risk of bias for separate domains as high, unclear, or low (Higgins 2011a; Higgins 2011b).

\section{Allocation sequence generation}

- Low risk of bias: sequence generation achieved using computer random number generation or a random number table. Drawing lots, tossing a coin, shuffling cards, or throwing dice are adequate if performed by an independent person, but not otherwise.

- Unclear risk of bias: not described.

- High risk of bias: the sequence generation method was not random.

\section{Allocation concealment}

- Low risk of bias: allocation by a central and independent randomisation unit, administration of coded, identical drug containers/vials or sequentially-numbered, opaque, sealed envelopes.

- Unclear risk of bias: not described.

- High risk of bias: the allocation sequence was likely to be known to the investigators who assigned the participants.

\section{Blinding of participants and personnel}

- Low risk of bias: Any of the following: no blinding or incomplete blinding, but the review authors judge that the outcome is not likely to be influenced by lack of blinding; or blinding of participants and key study personnel ensured, and it is unlikely that the blinding could have been broken.

- Unclear risk of bias: Any of the following: insufficient information to permit judgement of 'low risk' or 'high risk'; or the trial did not address this outcome.

- High risk of bias: Any of the following: no blinding or incomplete blinding, and the outcome is likely to be influenced by lack of blinding; or blinding of key study participants and personnel attempted, but likely that the blinding could have been broken, and the outcome is likely to be influenced by lack of blinding.

\section{Blinding of outcome assessors}

- Low risk of bias: Any of the following: no blinding of outcome assessment, but the review authors judge that the outcome measurement is not likely to be influenced by lack of blinding; or blinding of outcome assessment ensured, and unlikely that the blinding could have been broken.

- Unclear risk of bias: Any of the following: insufficient information to permit judgement of 'Low risk' or 'High risk'; or the trial did not address this outcome.

- High risk of bias: Any of the following: no blinding of outcome assessment, and the outcome measurement is likely to be influenced by lack of blinding; or blinding of outcome assessment, but likely that the blinding could have been broken, and the outcome measurement is likely to be influenced by lack of blinding.

\section{Incomplete outcome data}

- Low risk of bias: missing data unlikely to make treatment effects depart from plausible values. The investigators used 
Ammonia scavenging agents for people with cirrhosis and hepatic encephalopathy

sufficient methods, such as intention-to-treat analyses with multiple imputations or carry-forward analyses to handle missing data.

- Unclear risk of bias: insufficient information.

- High risk of bias: the results were likely to be biased due to missing data.

\section{Selective outcome reporting}

- Low risk of bias: the trial reported clinically-relevant outcomes (mortality, hepatic encephalopathy, and serious adverse events). If we had access to the original trial protocol, the outcomes selected were those called for in that protocol. If we obtained information from a trial registry (such as www.clinicaltrials.gov), we only used that information if the investigators registered the trial before inclusion of the first participant.

- Unclear risk of bias: not all predefined outcomes were reported fully, or it was unclear whether data on these outcomes were recorded or not.

- High risk of bias: one or more predefined outcomes were not reported.

\section{For-profit bias}

- Low risk of bias: the trial appears to be free of industry sponsorship or other type of for-profit support.

- Unclear risk of bias: insufficient information about support or sponsorship.

- High risk of bias: the trial received funding or other support from a pharmaceutical company.

\section{Other bias}

- Low risk of bias: the trial appeared to be free of other biases including: medicinal dosing problems or follow-up (as defined below).

- Unclear risk of bias: the trial may or may not have been free of other issues that could put it at risk of bias.

- High risk of bias: there were other factors in the trial that could put it at risk of bias such as the administration of inappropriate treatments being given to the controls (e.g. an inappropriate dose) or follow-up (e.g. the trial included different follow-up schedules for participants in the allocation groups).

\section{Overall bias assessment}

- Low risk of bias: all domains were classified as low risk of bias using the definitions described above.

- High risk of bias: one or more of the bias domains were classified as unclear or high risk of bias.

\section{Measures of treatment effect}

We will use risk ratios (RR) for dichotomous outcomes and mean differences (MD) for continuous outcomes, both with 95\% confidence intervals $(\mathrm{Cl})$. For outcomes suggesting that the interventions have a beneficial or harmful effect, we will calculate the number needed to treat for an additional beneficial outcome (NNTB) or number needed to treat for an additional harmful outcome (NNTH) based on the risk difference (RD) as 1/RD.

\section{Unit of analysis issues}

We will include data from the first treatment period of cross-over trials in our primary analyses (Higgins 2011a).

\section{Dealing with missing data}

We will collect data on all participants randomised, to allow intention-to-treat analyses including all participants irrespective of compliance or follow-up. We will perform a worst-case scenario analysis to evaluate the influence of missing data using simple imputation of missing values (Higgins 2008). In the worst-case scenario analysis, we will count all participants with missing outcomes as treatment failures. We will also conduct an extreme worst-case scenario analysis with missing outcome data counted as failures in the intervention group and successes in the control group.

\section{Assessment of heterogeneity}

We will express heterogeneity as $I^{2}$ values using the following thresholds: $0 \%$ to $40 \%$ (unimportant), $40 \%$ to $60 \%$ (moderate), $60 \%$ to $80 \%$ (substantial), and $>80 \%$ (considerable). We will include the information in the 'Summary of findings' tables.

\section{Assessment of reporting biases}

We will evaluate reporting bias based on the definition and reporting of key outcomes (the most clinically relevant) and by comparing protocols, online trial registrations, and trial publications. For meta-analyses with at least 10 trials, we will evaluate the risk of small study effects based on Egger's test for continuous outcomes (Egger 1997) and Harbord's test for dichotomous outcomes (Harbord 2006). The Egger's test performs a linear regression of the intervention effect estimates on their standard errors, weighting by $1 /$ (variance of the intervention effect). The Harbord test regresses Z/sqrt(V) against sqrt( $V)$, where $Z$ is the efficient score and $V$ is Fisher's information (the variance of $Z$ under the null hypothesis).

\section{Data synthesis}

We will perform the analysis in Review Manager (RevMan 2014), STATA 14 (Stata 2015), and Trial Sequential Analysis (TSA 2011).

\section{Meta-analyses}

We will analyse ammonia scavenger agents separately and plan to conduct fixed-effect and random-effects metaanalyses (Higgins 2011a). If the estimates of the random-effects and fixed-effect meta-analyses are similar, then we will assume that any small-study effects have little effect on the intervention effect estimate. If the random-effects estimate is 
Ammonia scavenging agents for people with cirrhosis and hepatic encephalopathy

more beneficial, we will re-evaluate whether it is reasonable to conclude that the intervention was more effective in the smaller studies. If the larger studies tend to be those conducted with greater methodological rigour, or conducted in circumstances more typical of the use of the intervention in practice, then we will report the results of meta-analyses restricted to the larger, more rigorous studies. Based on the expected clinical heterogeneity, we expect that a number of analyses will display statistical between-trial heterogeneity $\left(I^{2}>0 \%\right)$. For random-effects models, precision will decrease with increasing heterogeneity and confidence intervals will widen correspondingly. We therefore expect that the random-effects model will give the most conservative (and a more correct) estimate of the intervention effect. Accordingly, we plan to report the results of our analyses based on random-effects meta-analyses.

\section{Trial Sequential Analysis}

We plan to perform Trial Sequential Analyses for meta-analyses of our primary outcomes (Wetterslev 2008; TSA 2011; Higgins 2011b). We will define the required information size as the number of participants needed to detect or reject an intervention effect estimate, based on the event proportion in the control group and the diversity of the metaanalysis. We will define firm evidence as being established if the Z-curve crosses the trial sequential monitoring boundaries for benefit, harm, or futility before reaching the required information size. Based on previous evidence (AASLD and EASL Guideline 2014a; AASLD and EASL Guideline 2014b), we will conduct the analyses with alpha 5\%, power $80 \%$, and the Relative Risk Reduction/control event rate to $15 \% / 15 \%$ (mortality), $25 \% / 35 \%$ (hepatic encephalopathy), and $15 \% / 20 \%$ (serious adverse events).

\section{Subgroup analysis and investigation of heterogeneity}

We plan to perform the following subgroup analyses:

- bias control;

- type of encephalopathy;

- aetiology of liver disease (alcohol or hepatitis).

\section{Sensitivity analysis}

We will perform sensitivity analyses to evaluate publication status, and language, and conduct a worst-case scenario analysis as described above.

\section{'Summary of findings' table}

We will use the GRADE system (GradePro 2015) to evaluate the quality of the evidence for all outcomes reported in the review considering the within-study risk of bias (methodological quality), indirectness of evidence, heterogeneity, imprecision of effect estimate, and risk of publication bias.

\section{Results}

Description of studies

Results of the search

Included studies

Excluded studies

Risk of bias in included studies

Allocation (selection bias)

Blinding (performance bias and detection bias)

Incomplete outcome data (attrition bias)

Selective reporting (reporting bias)

Other potential sources of bias

Effects of interventions

\section{Discussion}

Summary of main results

Overall completeness and applicability of evidence

Quality of the evidence

Potential biases in the review process

Agreements and disagreements with other studies or reviews

\section{Authors' conclusions}

\section{Implications for practice}

Implications for research 


\section{Acknowledgements}

We would like to thank Sarah Klingenberg who prepared the preliminary search strategies for the electronic searches.

This review did not receive funding support.

Cochrane Review Group funding acknowledgement: The Danish State is the largest single funder of The Cochrane HepatoBiliary Group through its investment in The Copenhagen Trial Unit, Centre for Clinical Intervention Research, Rigshospitalet, Copenhagen University Hospital, Denmark.

Disclaimer: The views and opinions expressed in this review are those of the authors and do not necessarily reflect those of the Danish State or The Copenhagen Trial Unit.

Peer reviewers: Bruce F Scharschmidt, USA; Fernando Gomes Romeiro, Brazil; Baresh S Sharma, India; Peter Yepsen, Denmark.

Contact editors: Goran Bjelacovic, Serbia.

Sign-off editor: Christian Gluud, Denmark.

\section{Contributions of authors}

Lise L Gluud drafted the protocol and participated in the protocol revision. Alexandre Oliveira Ferreira worked on an earlier version of the protocol. The remaining authors have participated in the revision of the protocol and have approved of the final version.

\section{Declarations of interest}

Harry Zacharias: none.

Antony Zacharias: none.

Alexandre Oliveira Ferreira: none.

Marsha Y. Morgan: none.

Lise L Gluud: investigator in trials sponsored by Abbvie, Merck, and Norgine (money paid to institution); consultancy and travel expenses from Novo Nordisk.

\section{Differences between protocol and review}

\section{Published notes}

\section{Characteristics of studies}

Characteristics of included studies

Footnotes

Characteristics of excluded studies

Footnotes

Characteristics of studies awaiting classification

Footnotes

Characteristics of ongoing studies

Footnotes

Summary of findings tables

\section{Additional tables}

\section{Ammonia scavengers}


Ammonia scavenging agents for people with cirrhosis and hepatic encephalopathy

\begin{tabular}{|c|c|c|c|}
\hline $\begin{array}{l}\text { Ammonia } \\
\text { scavenger }\end{array}$ & Appearance & $\begin{array}{l}\text { Dose tested in } \\
\text { people with cirrhosis }\end{array}$ & Mechanism of action \\
\hline $\begin{array}{l}\text { Spherical carbon } \\
\text { adsorbent } \\
\text { (AST-120) }\end{array}$ & $\begin{array}{l}\text { Charcoal } \\
\text { powder }\end{array}$ & $\begin{array}{l}\text { Orally administered } \\
\text { powder (sachets), } \\
\text { two grams three } \\
\text { times daily }\end{array}$ & $\begin{array}{l}\text { Non-absorbable carbon microsphere }(0.2 \text { to } 0.4 \mathrm{~mm} \text { in diameter) } \\
\text { adsorbent, which is not degraded in the gastrointestinal lumen. }\end{array}$ \\
\hline $\begin{array}{l}\text { Glycerol } \\
\text { phenylbutyrate }\end{array}$ & Liquid & $\begin{array}{l}\text { Administered orally, } \\
\text { six ml twice daily for } \\
16 \text { weeks }\end{array}$ & $\begin{array}{l}\text { Prodrug of sodium phenylbutyrate. In the body, glutamine synthetase } \\
\text { facilitates the formation of glutamine from glutamate and ammonia. } \\
\text { Glycerol phenylbutyrate leads to formation of phenylacetylglutamine } \\
\text { from phenylacetate and glutamine. The compound is excreted in the } \\
\text { urine. The effect of the drug is therefore increased excretion of } \\
\text { ammonia. }\end{array}$ \\
\hline $\begin{array}{l}\text { Ornithine } \\
\text { phenylacetate }\end{array}$ & $\begin{array}{l}\text { Crystalline } \\
\text { salt }\end{array}$ & $\begin{array}{l}\text { Administered as } \\
\text { intravenous infusion } \\
10 \mathrm{~g} / 24 \mathrm{~h}(0.42 \mathrm{~g} / \mathrm{h})\end{array}$ & $\begin{array}{l}\text { Reduces ammonia through two pathways: i) L-ornithine acts as a } \\
\text { substrate for the synthesis of glutamine from ammonia in skeletal } \\
\text { muscle, and ii) phenylacetate and glutamine combines to form } \\
\text { phenylacetylglutamine, which is excreted in the urine. }\end{array}$ \\
\hline $\begin{array}{l}\text { Sodium } \\
\text { benzoate* }\end{array}$ & $\begin{array}{l}\text { Crystalline } \\
\text { powder }\end{array}$ & Not applicable & $\begin{array}{l}\text { Forms water soluble compounds that eliminate ammonia and } \\
\text { glutamate through the urine as phenylacetylglutamine. }\end{array}$ \\
\hline $\begin{array}{l}\text { Sodium } \\
\text { phenylacetate* }^{*}\end{array}$ & $\begin{array}{l}\text { Crystalline } \\
\text { powder }\end{array}$ & Not applicable & $\begin{array}{l}\text { Forms water soluble compounds that eliminate ammonia through the } \\
\text { urine as phenylacetylglutamine. }\end{array}$ \\
\hline $\begin{array}{l}\text { Polyethylene } \\
\text { glycol }\end{array}$ & $\begin{array}{l}\text { Electrolyte } \\
\text { solution }\end{array}$ & $\begin{array}{l}\text { Administered at a } \\
\text { dose of four litre } \\
\text { orally or via a } \\
\text { nasogastric tube }\end{array}$ & $\begin{array}{l}\text { A cathartic agent, which changes the bacterial flora in the gut thereby } \\
\text { reducing the uptake of ammonia. }\end{array}$ \\
\hline
\end{tabular}

Footnotes

*Include relatively high amounts of sodium.

\section{References to studies}

Included studies

Excluded studies

Studies awaiting classification

Ongoing studies

\section{Other references}

\section{Additional references}

\section{AASLD and EASL Guideline 2014a}

Vilstrup H, Amodio P, Bajaj J, Cordoba J, Ferenci P, Mullen KD, et al. Hepatic encephalopathy in chronic liver disease: 2014 Practice Guideline by the American Association for the Study of Liver Diseases and the European Association for the Study of the Liver. Hepatology (Baltimore, Md.) 2014;60:715-35.

\section{AASLD and EASL Guideline 2014b}

American Association for the Study of Liver Diseases, European Association for the Study of the Liver. Hepatic encephalopathy in chronic liver disease: 2014 practice guideline by the European Association for the Study of the Liver and the American Association for the Study of Liver Diseases. Journal of Hepatology 2014;61:642-59.

\section{Bajaj 2008}

Bajaj JS, Hafeezullah M, Franco J, Varma RR, Hoffmann RG, Knox JF, et al. Inhibitory control test for the diagnosis of minimal hepatic encephalopathy. Gastroenterology 2008;135:1591-600. [PubMed: 18723018]

\section{Bajaj 2010}

Bajaj JS, Schubert CM, Heuman DM, Wade JB, Gibson DP, Topaz A, et al. Persistence of cognitive impairment after resolution of overt hepatic encephalopathy. Gastroenterology 2010;138:2332-40. [PubMed: 20178797]

\section{Bajaj 2013}

Bajaj JS, Sheikh MY, Chojkier M, Balart L, Sherker AH, Vemuru R, et al. AST-120 (spherical carbon adsorbent) in covert hepatic encephalopathy: results of the astute trial. Journal of Hepatology 2013;58(Suppl 1):S84. [DOI:

10.1016/S0168-8278(13)60192-0]

\section{Bass 2010}




\section{Ammonia scavenging agents for people with cirrhosis and hepatic encephalopathy}

Bass NM, Mullen KD, Sanyal A, Poordad F, Neff G, Leevy CB, et al. Rifaximin treatment in hepatic encephalopathy. New England Journal of Medicine 2010;362:1071-81. [PubMed: 20335583]

\section{Berry 2014}

Berry SA, Lichter-Konecki U, Diaz GA, McCandless SE, Rhead W, Smith W, et al. Glycerol phenylbutyrate treatment in children with urea cycle disorders: pooled analysis of short and long-term ammonia control and outcomes. Molecular Genetics and Metabolism 2014;112:17-24. [PubMed: 24630270]

\section{Bosoi 2011}

Bosoi CR, Parent-Robitaille C, Anderson K, Tremblay M, Rose CF. AST-120 (spherical carbon adsorbent) lowers ammonia levels and attenuates brain edema in bile duct-ligated rats. Hepatology (Baltimore, Md.) 2011;53:1995-2002. [PubMed: 21384402]

\section{Butterworth 2013}

Butterworth RF. The liver-brain axis in liver failure: neuroinflammation and encephalopathy. Nature Reviews.

Gastroenterology \& Hepatology 2013;10:522-8. [PubMed: 23817325]

\section{Butterworth 2014}

Butterworth RF. Hepatic encephalopathy in alcoholic cirrhosis. Handbook of Clinical Neurology 2014;125:589-602. [. PubMed: 25307598]

\section{Cadranel 2001}

Cadranel JF, Lebiez E, Di Martino V, Bernard B, El Koury S, Tourbah A, et al. Focal neurological signs in hepatic encephalopathy in cirrhotic patients: an underestimated entity? American Journal of Gastroenterology 2001;96:515-8. [ PubMed: 11232699]

\section{Chu 1997}

Chu NS, Yang SS, Liaw YF. Evoked potentials in liver diseases. Journal of Gastroenterology and Hepatology 1997; 12:S288-93. [PubMed: 9407349]

\section{Conn 1977}

Conn HO, Leevy CM, Vlahcevic ZR, Rodgers JB, Maddrey WC, Seeff L, et al. Comparison of lactulose and neomycin in the treatment of chronic portal-systemic encephalopathy. A double blind controlled trial. Gastroenterology 1977;72:573-83. [_ PubMed: 14049]

\section{Efrati 2000}

Efrati C, Masini A, Merli M, Valeriano V, Riggio O. Effect of sodium benzoate on blood ammonia response to oral glutamine challenge in cirrhotic patients: a note of caution. American Journal of Gastroenterology 2000;95:3574-8. [PubMed: 11151894

\section{Egger 1997}

Egger M, Davey Smith G, Schneider M, Minder C. Bias in meta analysis detected by a simple, graphical test. BMJ (Clinical Research Ed.) 1997;315:629-34.

\section{Ferenci 2002}

Ferenci P. Hepatic encephalopathy--definition, nomenclature, diagnosis, and quantification: final report of the working party at the 11th World Congresses of Gastroenterology, Vienna, 1998. Hepatology (Baltimore, Md.) 2002;35:716-21.

\section{Gluud 2016a}

Gluud LL, Vilstrup H, Morgan MY. Non-absorbable disaccharides versus placebo/no intervention and lactulose versus lactitol for the prevention and treatment of hepatic encephalopathy in people with cirrhosis. Cochrane Database of Systematic Reviews 2016;5. [ Art. No.: CD003044 DOI: 10.1002/14651858.CD003044.pub4]

\section{Gluud 2016b}

Gluud LL, Vilstrup H, Morgan MY. Non-absorbable disaccharides for hepatic encephalopathy: a systematic review and metaanalysis. Hepatology 2016 Apr 15 [Epub ahead of print]. [DOI: 10.1002/hep.28598]

\section{Gluud 2016c}

Gluud C, Nikolova D, Klingenberg SL. Cochrane Hepato-Biliary Group. About Cochrane (Cochrane Review Groups (CRGs)). Cochrane Library 2016;(4).

\section{GradePro 2015}

GRADEpro GDT [Computer program]. Version accessed 16 August 2016. Hamilton (ON): McMaster University (developed by Evidence Prime, Inc.), 2015.

\section{Guérit 2009}

Guérit JM, Amantini A, Fischer C, Kaplan PW, Mecarelli O, Schnitzler A, et al. Neurophysiological investigations of hepatic encephalopathy: ISHEN practice quidelines. Liver International 2009;29:789-96. 「 PubMed: 19638107] 


\section{Harbord 2006}

Harbord RM, Egger M, Sterne JA. A modified test for small-study effects in meta-analyses of controlled trials with binary endpoints. Statistics in Medicine 2006;25:3443-57. [PubMed: 16345038]

\section{Haussinger 2000}

Haussinger D, Kircheis G, Fischer R, Schliess F, vom Dahl S. Hepatic encephalopathy in chronic liver disease: a clinical manifestation of astrocyte swelling and low-grade cerebral edema? Journal of Hepatology 2000;32:1035-8. [PubMed: $10898326]$

\section{Higgins 2008}

Higgins JPT, White IR, Wood AM. IImputation methods for missing outcome data in meta-analysis of clinical trials. Clinical Trials 2008;5:225-39.

\section{Higgins 2011a}

Higgins JPT, Green S (editors). Cochrane Handbook for Systematic Reviews of Interventions Version 5.1.0 [updated March 2011]. The Cochrane Collaboration, 2011. Available from www.cochrane-handbook.org.

\section{Higgins 2011b}

Higgins JP, Whitehead A, Simmonds M. Sequential methods for random-effects meta-analysis. Statistics in Medicine 2011; 30:903-21.

\section{ICH-GCP}

International conference on harmonisation of technical requirements for registration of pharmaceuticals for human use. ICH harmonised tripartite guideline. Guideline for good clinical practice CFR \& ICH Guidelines.

http://www.ich.org/products/guidelines/safety/article/safety-guidelines.html [accessed 18 August, 2016].

Jalan 2007

Jalan R, Wright G, Davies NA, Hodges SJ. L-Ornithine phenylacetate (OP): a novel treatment for hyperammonemia and hepatic encephalopathy. Medical Hypotheses 2007;69:1064-9. [PubMed: 17467190]

\section{Jover-Cobos 2013}

Jover-Cobos M, Noiret L, Sharifi Y, Jalan R. Ornithine phenylacetate revisited. Metabolic Brain Disease 2013;28:327-31. [ PubMed: 23456516

\section{Kircheis 2002}

Kircheis G, Wettstein M, Timmermann L, Schnitzler A, Haussinger D. Critical flicker frequency for quantification of low-grade hepatic encephalopathy. Hepatology (Baltimore, Md.) 2002;35:357-66. [PubMed: 11826409]

\section{Lee 2010}

Lee B, Rhead W, Diaz GA, Scharschmidt BF, Mian A, Shchelochkov O, et al. Phase 2 comparison of a novel ammonia scavenging agent with sodium phenylbutyrate in patients with urea cycle disorders: safety, pharmacokinetics and ammonia control. Molecular Genetics and Metabolism 2010;100:221-8. [PubMed: 20382058]

\section{McGuire 2010}

McGuire BM, Zupanets IA, Lowe ME, Xiao X, Syplyviy VA, Monteleone J, et al. Pharmacology and safety of glycerol phenylbutyrate in healthy adults and adults with cirrhosis. Hepatology (Baltimore, Md.) 2010;51:2077-85. [ PubMed: 20512995]

\section{MECIR 2014}

Methodological Expectations of Cochrane Intervention Reviews (MECIR). www.editorial-unit.cochrane.org/mecir 2014 (accessed 25 August 2016).

\section{Misel 2013}

Misel ML, Gish RG, Patton H, Mendler M. Sodium benzoate for treatment of hepatic encephalopathy. Gastroenterology \& Hepatology 2013;9:219-27. [PubMed: 24711766]

\section{Montagnese 2004}

Montagnese S, Amodio P, Morgan MY. Methods for diagnosing hepatic encephalopathy in patients with cirrhosis: a multidimensional approach. Metabolic Brain Disease 2004;19:281-312. [PubMed: 15554423]

\section{NCT00558038}

NCT00558038. Safety and efficacy of AST-120 compared to lactulose in patients with hepatic encephalopathy (AST015). clinicaltrials.gov/ct2/show/NCT00558038 (accessed 1 June 2016).

\section{NCT01966419}

NCT01966419. Phase 2B efficacy/safety of ornithine phenylacetate in hospitalized cirrhotic patients with hepatic encephalopathy (STOP-HE). clinicaltrials.gov/ct2/show/NCT01966419?term=NCT01966419\&rank=1 (accessed 1 June 
2016).

\section{O'Carroll 1991}

O'Carroll RE, Hayes PC, Ebmeier KP, Dougall N, Murray C, Best JJ, et al. Regional cerebral blood flow and cognitive function in patients with chronic liver disease. Lancet 1991;337:1250-3. [PubMed: 1674063]

\section{Pockros 2009}

Pockros P, Hassanein T, Vierling J, Heuman D, Hillebrand D, Chojkier M. Phase 2, multicenter, randomized study of AST-120 (spherical carbon adsorbent) vs. lactulose in the treatment of low-grade hepatic encephalopathy (HE). Journal of Hepatology 2009;50(Suppl 1):S43. [Other: CN-00715816]

\section{Rahimi 2016}

Rahimi RS, Rockey DC. Hepatic encephalopathy: pharmacological therapies targeting ammonia. Seminars in Liver Disease 2016;36:48-55. [PubMed: 26870932]

\section{Randolph 2009}

Randolph C, Hilsabeck R, Kato A, Kharbanda P, Li YY, Mapelli D, et al. Neuropsychological assessment of hepatic encephalopathy: ISHEN practice guidelines. Liver International 2009;29:629-35. [PubMed: 19302444]

\section{RevMan 2014}

Review Manager (RevMan) [Computer program]. Version 5.3. Copenhagen: Nordic Cochrane Centre, The Cochrane Collaboration, 2014.

\section{Rockey 2014}

Rockey DC, Vierling JM, Mantry P, Ghabril M, Brown RS Jr, Alexeeva O, et al. Randomized, double-blind, controlled study of glycerol phenylbutyrate in hepatic encephalopathy. Hepatology (Baltimore, Md.) 2014;59:1073-83. [PubMed: 23847109]

\section{Rose 2012}

Rose CF. Ammonia-lowering strategies for the treatment of hepatic encephalopathy. Clinical Pharmacology and Therapeutics 2012;92:321-31. [PubMed: 22871998]

\section{Schomerus 1998}

Schomerus H, Hamster W. Neuropsychological aspects of portal-systemic encephalopathy. Metabolic Brain Disease 1998; 13:361-77. [ PubMed: 10206827]

\section{Sherker 2009}

Sherker AH, Vierling JM, Pockros P, Battish R, LaPlaca C, Resler M. Oral AST-120 (spherical carbon adsorbent) improves pruritus and lowers serum bile acids in patients with cirrhosis of various etiologies. Hepatology (Baltimore, Md.) 2009;50:462A-3A. [Other: CN-00739661]

\section{Stata 2015}

Stata: Release 14 [Computer program]. Texas, USA: Stata Corp, 2015.

\section{Stepanova 2012}

Stepanova M, Mishra A, Venkatesan C, Younossi ZM. In-hospital mortality and economic burden associated with hepatic encephalopathy in the United States from 2005 to 2009. Clinical Gastroenterology and Hepatology 2012;10:1034-41.

\section{Stokes 2016}

Stokes C, Teng E, Vilstrup H, Gluud L, Morgan M. L-ornithine I-aspartate for people with cirrhosis and hepatic encephalopathy (in press). Cochrane Database for Systematic Reviews 2016.

\section{Sushma 1992}

Sushma S, Dasarathy S, Tandon RK, Jain S, Gupta S, Bhist MS. Sodium benzoate in the treatment of acute hepatic encephalopathy: a double-blind randomized trial. Hepatology (Baltimore, Md.) 1992;16:138-44. [PubMed: 1618465]

\section{Taylor-Robinson 1994}

Taylor-Robinson SD, Sargentoni J, Marcus CD, Morgan MY, Bryant DJ. Regional variations in cerebral proton spectroscopy in patients with chronic hepatic encephalopathy. Metabolic Brain Disease 1994;9:347-59. [PubMed: 7898401]

\section{Teasdale 1974}

Teasdale G, Jennett B. Assessment of coma and impaired consciousness. A practical scale. Lancet 1974;2:81-4. [PubMed: 4136544]

TSA 2011

TSA - Trial Sequential Analysis [Computer program]. Version 0.9 Beta. Copenhagen: Copenhagen Trial Unit, 2011.www.ctu.dk/tsa/downloads.aspx. 
Ammonia scavenging agents for people with cirrhosis and hepatic encephalopathy

Ventura-Cots M, Arranz JA, Simon-Talero M, Torrens M, Blanco A, Riudor E, et al. Safety of ornithine phenylacetate in cirrhotic decompensated patients: an open-label, dose-escalating, single-cohort study. Journal of Clinical Gastroenterology 2013;47:881-7. [PubMed: 23751856]

\section{Victor 1965}

Victor M, Adams RD, Cole M. The acquired (non-Wilsonian) type of chronic hepatocerebral degeneration. Medicine 1965; 44:345-96. [PubMed: 5318075]

\section{Weissenborn 1998}

Weissenborn K. Diagnosis of encephalopathy. Digestion 1998;59(Suppl 2):22-4.

\section{Weissenborn 2001}

Weissenborn K, Ennen JC, Schomerus H, Ruckert N, Hecker H. Neuropsychological characterization of hepatic encephalopathy. Journal of Hepatology 2001;34:768-73. [PubMed: 11434627]

\section{Wetterslev 2008}

Wetterslev J, Thorlund K, Brok J, Gluud C. Trial sequential analysis may establish when firm evidence is reached in cumulative meta-analysis. Journal of Clinical Epidemiology 2008;61:64-75.

\section{Wu 2014}

Wu HM, Sun HJ, Wang F, Yang M, Dong BR, Liu GJ. Oral adsorbents for preventing or delaying the progression of chronic kidney disease. Cochrane Database of Systematic Reviews 2014, Issue 10. Art. No.: CD007861 DOI:

10.1002/14651858.CD007861.pub2.

Other published versions of this review

Classification pending references

\section{Data and analyses}

\section{Figures}

\section{Sources of support}

Internal sources

- No funding, Other

\section{External sources}

- No funding, Other

\section{Feedback}

\section{Appendices}

1 Search strategy

\begin{tabular}{|c|c|c|}
\hline Database & Time span & Search terms \\
\hline $\begin{array}{l}\text { The Cochrane Hepato- } \\
\text { Biliary Group Controlled } \\
\text { Trials Register }\end{array}$ & $\begin{array}{l}\text { Date to be } \\
\text { given at } \\
\text { review } \\
\text { stage. }\end{array}$ & $\begin{array}{l}\text { (glycerol phenylbutyrat* or ravicti or ornithine phenylacetat* or OCR-002 or } \\
\left(\text { ammoni }^{*} \text { and scaveng*)) AND (encephalopath* or liver disease }{ }^{*} \text { or cirrho* }\right)\end{array}$ \\
\hline $\begin{array}{l}\text { Cochrane Central } \\
\text { Register of Controlled } \\
\text { Trials (CENTRAL) } \\
\text { (Cochrane Library) }\end{array}$ & Latest issue. & $\begin{array}{l}\text { \#1 } \text { glycerol phenylbutyrat }^{*} \text { or ravicti or ornithine phenylacetat* or OCR-002 or } \\
\text { (ammoni* and scaveng*) } \\
\text { \#2 MeSH descriptor: [Hepatic Encephalopathy] explode all trees } \\
\text { \#3 MeSH descriptor: [Liver Diseases] explode all trees } \\
\text { \#4 MeSH descriptor: [Fibrosis] explode all trees } \\
\text { \#5 (encephalopath* or liver disease* or cirrho*) } \\
\# 6 \text { \#2 or \#3 or \#4 or \#5 } \\
\text { \#7 \#1 and \#6 }\end{array}$ \\
\hline
\end{tabular}


Ammonia scavenging agents for people with cirrhosis and hepatic encephalopathy

\begin{tabular}{|c|c|c|}
\hline Database & Time span & Search terms \\
\hline MEDLINE (Ovid SP) & $\begin{array}{l}1946 \text { to the } \\
\text { date of } \\
\text { search. }\end{array}$ & $\begin{array}{l}\text { 1. (glycerol phenylbutyrat* or ravicti or ornithine phenylacetat* or OCR-002 or } \\
\text { (ammoni* and scaveng*)).mp. [mp=title, abstract, original title, name of substance } \\
\text { word, subject heading word, keyword heading word, protocol supplementary } \\
\text { concept word, rare disease supplementary concept word, unique identifier] } \\
\text { 2. exp Hepatic Encephalopathy/ } \\
\text { 3. exp Liver Diseases/ } \\
\text { 4. exp Fibrosis/ } \\
\text { 5. (encephalopath* or liver disease* or cirrho*).mp. [mp=title, abstract, original title, } \\
\text { name of substance word, subject heading word, keyword heading word, protocol } \\
\text { supplementary concept word, rare disease supplementary concept word, unique } \\
\text { identifier] } \\
\text { 6. } 2 \text { or } 3 \text { or } 4 \text { or } 5 \\
\text { 7. } 1 \text { and } 6 \\
\text { 8. (random* or blind* or placebo* or meta-analys }{ }^{*} \text { ).mp. [mp=title, abstract, original } \\
\text { title, name of substance word, subject heading word, keyword heading word, } \\
\text { protocol supplementary concept word, rare disease supplementary concept word, } \\
\text { unique identifier] } \\
\text { 9. } 7 \text { and } 8\end{array}$ \\
\hline Embase (Ovid SP) & $\begin{array}{l}1974 \text { to the } \\
\text { date of } \\
\text { search. }\end{array}$ & $\begin{array}{l}\text { 1. (glycerol phenylbutyrat* or ravicti or ornithine phenylacetat* or OCR-002 or } \\
(\text { ammoni* and scaveng*)).mp. [mp=title, abstract, heading word, drug trade name, } \\
\text { original title, device manufacturer, drug manufacturer, device trade name, keyword] } \\
\text { 2. exp hepatic encephalopathy/ } \\
\text { 3. exp liver disease/ } \\
\text { 4. exp fibrosis/ } \\
\text { 5. (encephalopath* or liver disease* or cirrho*).mp. [mp=title, abstract, heading } \\
\text { word, drug trade name, original title, device manufacturer, drug manufacturer, } \\
\text { device trade name, keyword] } \\
\text { 6. } 2 \text { or } 3 \text { or } 4 \text { or } 5 \\
\text { 7. } 1 \text { and } 6 \\
\text { 8. (random* or blind* or placebo* or meta-analys }{ }^{*} \text { ).mp. [mp=title, abstract, heading } \\
\text { word, drug trade name, original title, device manufacturer, drug manufacturer, } \\
\text { device trade name, keyword] } \\
\text { 9. } 7 \text { and } 8\end{array}$ \\
\hline $\begin{array}{l}\text { Science Citation Index } \\
\text { Expanded (Web of } \\
\text { Science) }\end{array}$ & $\begin{array}{l}1900 \text { to the } \\
\text { date of } \\
\text { search. }\end{array}$ & $\begin{array}{l}\text { \#5 \#4 AND \#3 } \\
\text { \#4 TS=(random* or blind* or placebo* or meta-analys*) } \\
\text { \#3 \#2 AND \#1 } \\
\text { \#2 TS=(encephalopath* or liver disease* or cirrho*) } \\
\text { \#1 TS=(glycerol phenylbutyrat* or ravicti or ornithine phenylacetat* or OCR-002 or } \\
\left.\left(\text { ammoni }^{*} \text { and scaveng }{ }^{*}\right)\right)\end{array}$ \\
\hline
\end{tabular}

